\title{
Carbon-13 Nuclear Magnetic Resonance Spectroscopy of Poly(vinyl acetate) and Poly(vinyl alcohol)
}

\author{
Yoshio Inoue, Riichirô Chûjô, and Atsuo Nishioka \\ Department of Polymer Engineering, Tokyo Institute of Technology, \\ 12-1 Ookayama 2-Chome, Meguro-ku, Tokyo, Japan. \\ Shun-ichi Nozakura and Hiroyuki Immuro \\ Faculty of Science, Osaka University, 1-1 Machikane-cho, \\ Toyonaka, Osaka, Japan.
}

(Received March 17, 1972)

\begin{abstract}
The carbon-13 high resolution nuclear magnetic resonance spectra with proton spin decoupling have been obtained for poly(vinyl acetate) and poly(vinyl alcohol). Carbon-13 resonances of the skeletal carbons of poly(vinyl acetate) are more sensitive to the steric configuration than those of the side-chain carbons. The spectra of $\alpha$-methine carbons of poly(vinyl alcohol) have clear splits corresponding to triad and (partially) to pentad placements. By comparing the results of carbon-13 spectra with those of proton spectra, it was confirmed that the nuclear Overhauser effect due to the proton decoupling has no influence on the estimation of microtacticity through the relative intensities of peaks in the carbon-13 spectra.

It was shown that the detection and estimation of the branches in poly(vinyl alcohol) might be possible by using the carbon-13 resonance.

KEY WORDS ${ }^{13} \mathrm{C}-\left\{{ }^{1} \mathrm{H}\right\}$ NMR / Poly(vinyl acetate) / Poly(vinyl alcohol) / Configuration / Branch / Tacticity / Nuclear Overhauser Effect /
\end{abstract}

The use of completely proton decoupled carbon-13 nuclear magnetic resonance spectra $\left({ }^{13} \mathrm{C}-\left\{{ }^{1} \mathrm{H}\right\} \mathrm{NMR}\right)$ in the elucidation of polymer structures is well established, ${ }^{1-10}$ and these results confirm the potential of carbon-13 NMR as a means of characterizing polymer microstructure.

Many studies on the estimation of the microtacticity of poly(vinyl acetate) (PVAc) and poly(vinyl alcohol) (PVA) have been made using proton magnetic resonance $\left({ }^{1} \mathrm{H}\right.$ NMR).${ }^{11-20}$ The triad microtacticity of PVAc can be obtained from the side-chain methyl proton spectrum, and diad and triad microtacticities of PVA can be obtained from the decoupled spectra of $\alpha$ and $\beta$-protons. The determination of accurate microtacticity of these polymers from ${ }^{1} \mathrm{H}$ NMR is rather intricate due to small differences in chemical shifts and to problems in obtaining optimum decoupling.

In this paper are reported the results of the measurements of configutional sequences in
PVA $_{c}$ and PVA by direct ${ }^{13} \mathrm{C}$ observations on unenriched samples. The results of ${ }^{13} \mathrm{C}$ NMR measurements were compared with those of ${ }^{1} \mathrm{H}$ NMR measurements to examine the applicability of the ${ }^{13} \mathrm{C}$ NMR to the characterization of PVAc and PVA. Furthermore the preliminary results of attempts to detect branching in a model polymer of PVA by using the ${ }^{12} \mathrm{C}$ NMR are reported.

\section{EXPERIMENTAL}

\section{Material}

PVA-A (DP 3150) was expected to have a high isotacticity and was prepared by hydrolysis of poly(vinyl trimethylsilyl ether), which was itself prepared by the polymerization of vinyl trimethylsilyl ether with $\mathrm{EtAlCl}_{2}$ as a catalyst in toluene at $-95^{\circ} \mathrm{C}$. Detailed methods of preparation for this polymer are described elsewhere. $^{21}$

PVA-B (DP 1500) was commercially available 
polymer obtained from Kuraray Co. Ltd.

PVAc-A and PVAc-B were derived from the sample PVA-A and PVA-B, respectively, by acetylation with acetic anhydride and pyridine.

PVA-C (DP 600) was a model polymer of PVA having short branches and was prepared by hydrolysis of copolymer of vinyl acetate $\left(\mathbf{M}_{1}\right)$ and 2,4-diacetoxy-1-butene $\left(\mathbf{M}_{2}\right)$. This copolymer is considered to have a structure of

[I]<smiles>CCC(O)C(O)C(Cl)CO</smiles>

where the copolymer composition was $m: n=$ $7: 1$ and its randomness is somewhat different from Bernoulli trial, because of the monomer reactivity ratios $r_{1}=1.63$ and $r_{2}=0.52$. Details of the preparation of the copolymer will be described elsewhere. ${ }^{22}$

\section{Methods}

The NMR spectra of PVA were observed in $\mathrm{D}_{2} \mathrm{O}$ at $100^{\circ} \mathrm{C}$ and those of PVAc were in $\mathrm{CHCl}_{3}$ for ${ }^{13} \mathrm{C}$ and in $\mathrm{CDCl}_{3}$ for ${ }^{1} \mathrm{H}$ NMR at $70^{\circ} \mathrm{C}$. These spectra were measured using a Japan Electron Optics Laboratory JNM PS-100 spectrometer operated at $100 \mathrm{MHz}$ for ${ }^{1} \mathrm{H}$ and $25.14 \mathrm{MHz}$ for ${ }^{13} \mathrm{C}$. The ${ }^{13} \mathrm{C}$ spectra were observed by an external locked field sweep in the absorption mode with complete proton decoupling. The effective signal-to-noise ratio was improved by means of the multiple scan average technique using a JNM JEC-5 spectrum computer. For the ${ }^{13} \mathrm{C}$ measurement the samples were filled into $8-\mathrm{mm}$ glass tubes. Chemical shifts in ${ }^{13} \mathrm{C}$ spectra are expressed in parts per million with respect to the peak of ${ }^{13} \mathrm{C}$ enriched carbonyl carbon atom of $\mathrm{CH}_{3} \mathrm{COOH}$ which was was used as an external reference. The microtacticity was determined by the area measurements of the corresponding peaks.

\section{RESULTS AND' DISCUSSION}

\section{Poly(vinyl acetate)}

The stereochemical configuration of PVAc has been the subject of many ${ }^{1} \mathrm{H}-\mathrm{NMR}$ investigations. ${ }^{11-16}$ The resonances of the $\alpha$ - and $\beta$ proton of PVAc are rather complex due to proton coupling and the overlapping of the large number of polyads each of which is slightly different in its chemical shift. The 100 $\mathrm{MHz}{ }^{1} \mathrm{H}$ NMR spectra of the side-chain methyl group and $\beta$-methylene group of PVAc-A and $B$ are shown in Figure 1. The three components of the resonances corresponding to the sidechain methyl group were assigned to isotactic $(m m)$, heterotactic $(m r)$, and syndiotactic ( $r r)$ triads with increasing field strength, respective$1 y .^{12,14,15}$ (The streochemical notation used here is that proposed by Frisch, et al. ${ }^{17}$ ) The relative intensities of triad microtacticity of PVAc determined from Figure 1 are tabulated at the upper two rows in Table I. These results indicate that the PVAc-A is highly isotactic and the PVAc-B is essentially atactic. Referring to these data, an attempt was made to assign the

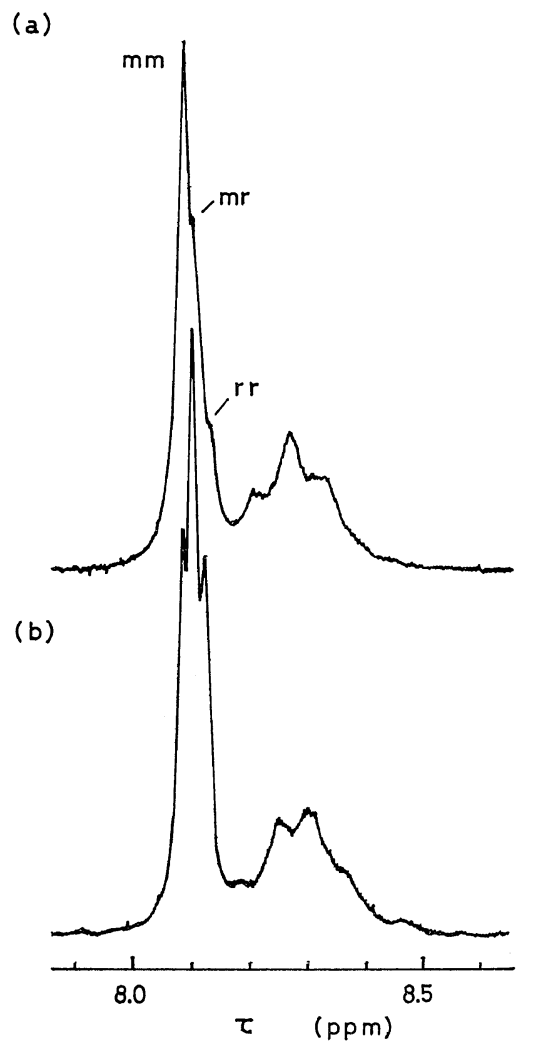

Figure 1. ${ }^{1} \mathrm{H}$ spectra of methyl and methylene groups of PVAc observed at $100 \mathrm{MHz}$, in $10-\%$ (w/v) solution in $\mathrm{CDCl}_{3}$ at $70^{\circ} \mathrm{C}$ : (a) PVAc-A; (b) PVAc-B. 
Table I. The microtacticity of poly(vinyl acetate) and poly(vinyl alcohol)

\begin{tabular}{|c|c|c|c|c|}
\hline \multirow{2}{*}{ Samples } & \multicolumn{3}{|c|}{ Triad tacticity } & \multirow{2}{*}{$\frac{4(m m)(r r)}{(m r)^{2}}$} \\
\hline & $(m m)$ & $(m r)$ & $(r r)$ & \\
\hline PVAc-A & 0.67 & 0.25 & $0.08^{a}$ & 3.43 \\
\hline PVAc-B & 0.23 & 0.48 & $0.29^{a}$ & 1.16 \\
\hline PVA-A & 0.65 & 0.27 & $0.08^{b}$ & 2.85 \\
\hline PVA-B & 0.22 & 0.50 & $0.28^{d}$ & 0.99 \\
\hline
\end{tabular}

a From area measurements of ${ }^{1} \mathrm{H}$ NMR spectra of side-chain methy group.

b From area measurements of ${ }^{13} \mathrm{C}-\left\{{ }^{1} \mathrm{H}\right\}$ NMR spectra of $\alpha$-methine carbon.

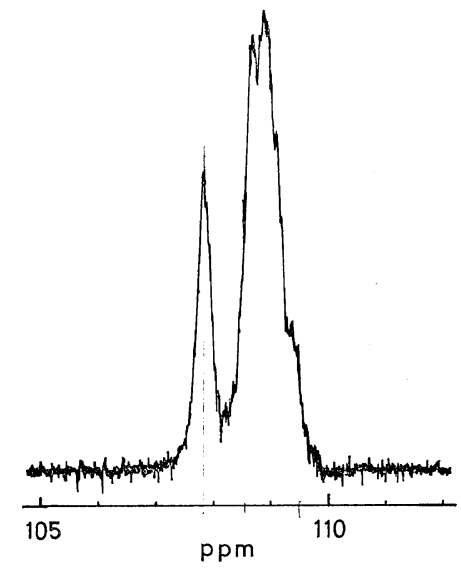

Figure 2. ${ }^{13} \mathrm{C}-\left\{{ }^{1} \mathrm{H}\right\}$ spectrum of methine carbon of PVAc-B observed at $25.14 \mathrm{MHz}$ in $40-\%(\mathrm{w} / \mathrm{v})$ solution in $\mathrm{CHCl}_{3}$ at $70^{\circ} \mathrm{C}$ (256 scans). The sweep rate for each scan was $27 \mathrm{ppm} / 250 \mathrm{sec}$.

${ }^{13} \mathrm{C}-\left\{{ }^{1} \mathrm{H}\right\}$ spectra of PVAc and PVA as in the following section.

${ }^{13} \mathrm{C}-\left\{{ }^{1} \mathrm{H}\right\} \quad$ NMR spectrum of the $\alpha$-methine carbon of PVAc-B consists of two main peaks as shown in Figure 2. The relative intensities between these two peaks were 0.22 for the lower, and 0.78 for the upper field peaks, respectively. Therefore the lower field peak could be assigned to the isotactic triad and the upper one to the overlap of the heterotactic and syndiotactic triads. The nuclear Overhauser effect caused by the proton decoupling should not affect the relative intensities of the resonances of carbons which differ only in the configurations discussed below. It is noteworthy that the lower field peak is a single broad line

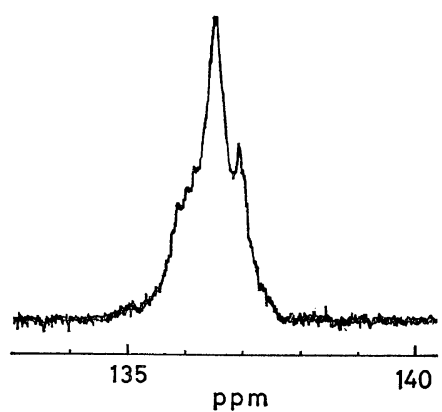

Figure 3. ${ }^{13} \mathrm{C}-\left\{{ }^{1} \mathrm{H}\right\}$ spectrum of methylene carbon of PVAc-B observed under the same conditions as in Figure 2. (a)

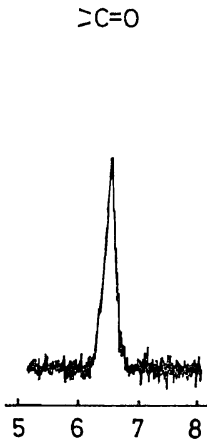

(b)

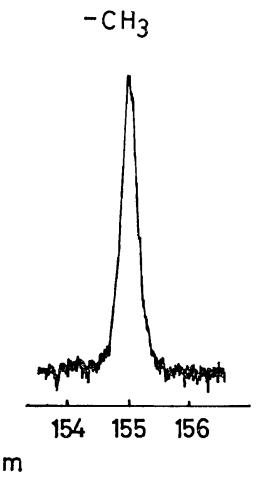

Figure 4. ${ }^{13} \mathrm{C}-\left\{{ }^{1} \mathrm{H}\right\}$ spectra of the carbonyl carbon (a) and the methyl carbon (b) of PVAc-B (64 scans), observed under the same conditions as in Figure 2.

in contrast with upper one which shows rather complicated splitting and the analysis on the basis of the triad is inadequate. However the chemical shifts and resolution are insufficient to allow pentad assignments.

The ${ }^{13} \mathrm{C}-\left\{{ }^{1} \mathrm{H}\right\}$ NMR spectrum of $\beta$-methylene carbon of PVAc-B is complex as shown in Figure 3. This resonance is complicated by the influence of the overlapping of peaks separated by tetrads.

In Figure 4 are shown the ${ }^{13} \mathrm{C}-\left\{{ }^{1} \mathrm{H}\right\}$ NMR spectra of the side-chain carbons of PVAc-B, i.e., the carbonyl and the methyl carbons. These spectra are rather broad but each has a single peak. This result shows that the resonances of the side-chain carbon atoms are little 
affected by the polymer stereochemistry. Since the side-chain methyl group shows fine splitting due to the triad in ${ }^{1} \mathrm{H}$ resonance, the above result is interesting in the theoretical study of chemical shifts. Since the authors have already reported that the ${ }^{13} \mathrm{C}-\left\{{ }^{1} \mathrm{H}\right\}$ resonance of the sidechain carbonyl carbon of poly(methyl methacrylate) clearly shows pentad splitting, ${ }^{8}$ a single peak for PVAc is an unexpected result.

In conclusion, the ${ }^{13} \mathrm{C}-\left\{{ }^{1} \mathrm{H}\right\}$ resonances of the skeletal carbons of PVAc appear to be more sensitive to the steric configuration than those of the side-chain carbons.

\section{Poly(vinyl alcohol)}

The stereochemical configuration in PVA has also been investigated by many authors using ${ }^{1} \mathrm{H}$ NMR. ${ }^{13-15,18-20}$ The resonances of the $\alpha$ and $\beta$-skeletal protons of PVA are complex due to proton coupling as shown in Figure $5 \mathrm{a}$. The spectra of PVA-B shown in Figure 5 were observed at $100 \mathrm{MHz}$ in $\mathrm{D}_{2} \mathrm{O}$ solution at $100^{\circ} \mathrm{C}$ and a small amount of $\mathrm{H}_{2} \mathrm{SO}_{4}$ was added to shift the hydroxyl proton resonance to downfield. ${ }^{16}$

In Figures $5 \mathrm{~b}$ and $5 \mathrm{c}$ are shown the resonance of the $\alpha$-proton decoupled from the $\beta$-proton and of the $\beta$-proton decoupled from the $\alpha$ proton. The decoupling was carried out by a double irradiation technique and the spectra were observed by the external locked field sweep method.

The decoupled $\beta$-proton exhibits two components corresponding to the isotactic and syndiotactic diads with increasing field strength. However since the undecoupled resonance of the $\alpha$-protons is considered to consist of three overlapping quintets, the decoupling by the double irradiation technique may be insufficient to estimate diad tacticity from the relative intensities of the two peaks of the decoupled $\beta$ proton. This is because it is quite difficult to get the completely decoupled spectrum consisting of different chemical shifts, although there have been many papers measuring tacticity only by double resonance.

The decoupled $\alpha$-proton exhibits three components corresponding to the syndiotactic, heterotactic, and isotactic triads with increasing field strength. The undecoupled resonance of the $\beta$ -

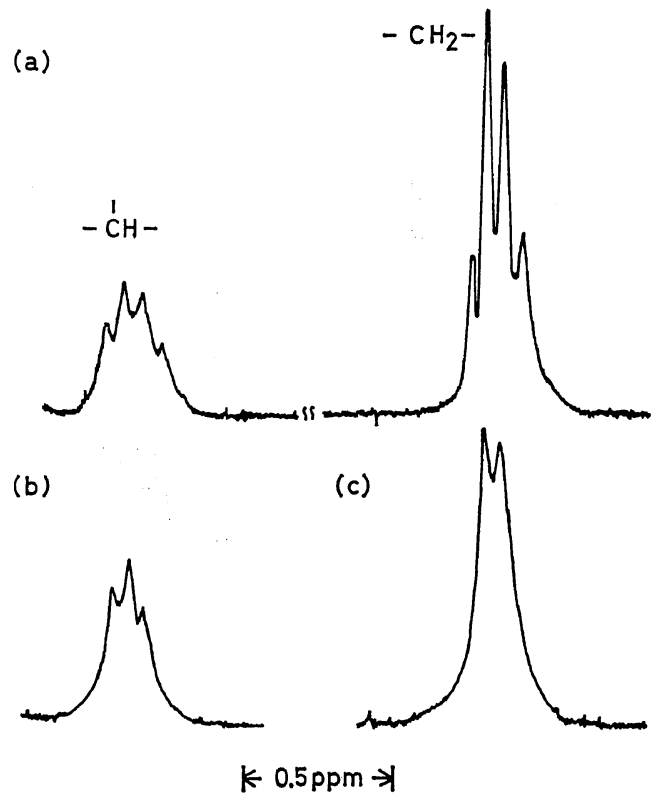

Figure 5. ${ }^{1} \mathrm{H}$ spectra of PVA-B observed at 100 $\mathrm{MHz}$, in $7-\%(\mathrm{w} / \mathrm{v})$ solution in $\mathrm{D}_{2} \mathrm{O}$ at $100^{\circ} \mathrm{C}$ : (a) normal spectrum; (b) $\alpha$-proton resonance decoupled from the $\beta$-proton; (c) $\beta$-proton resonance decoupled from the $\alpha$-proton. A trace of $\mathrm{H}_{2} \mathrm{SO}_{4}$ was added.

proton is considered to consist of two overlapping triplets. ${ }^{16}$ The decoupling by double irradiation technique may therefore be insufficient and the relative intensities of the three peaks of the decoupled $\alpha$-proton cannot be related directly to triad tacticity even if the saturation and the different enhancements due to Overhauser effects $^{23,24}$ do not occur. In practice, it is dangerous to adopt the intensities of protonproton spin decoupled ${ }^{1} \mathrm{H}$ NMR resonance for the quantitative usage becase it is difficult to control the saturation and the Overhauser effects. ${ }^{15}$

${ }^{13} \mathrm{C}-\left\{{ }^{1} \mathrm{H}\right\}$ spectra of the methine carbon of PVA are shown in Figure 6. The resonances of the methine carbon fall into three distinct groups which have been assigned as indicated in Figure $6 \mathrm{a}$ to isotactic, heterotactic, and syndiotactic triads on the basis of the triad tacticity obtained from the ${ }^{1} \mathrm{H}$ NMR spectra of PVAc. The ${ }^{13} \mathrm{C}$ chemical shift differences between $\mathrm{mm}$ and $m r$, and between $m r$ and $r r$ are both about $1.5 \mathrm{ppm}$, while the ${ }^{1} \mathrm{H}$ chemical shift differences 


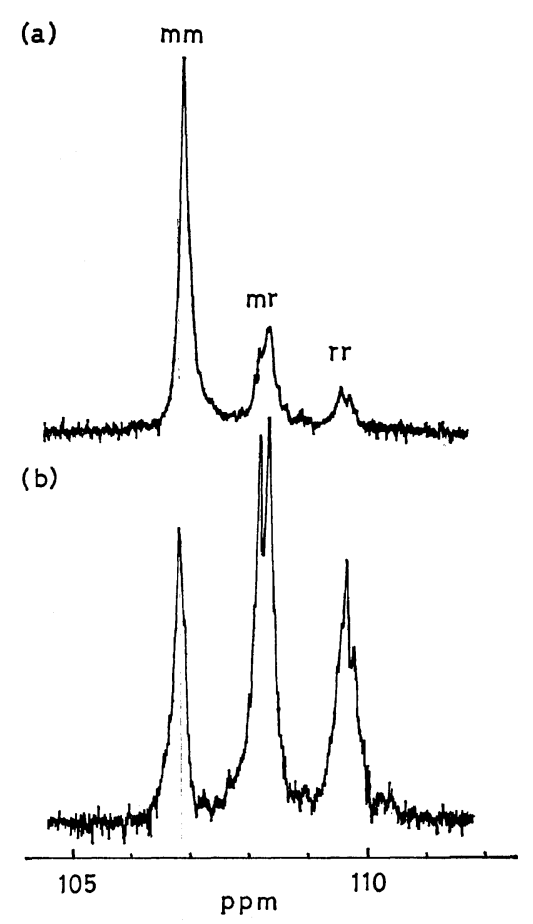

Figure 6. ${ }^{13} \mathrm{C}-\left\{{ }^{1} \mathrm{H}\right\}$ spectra of methine carbon of PVA observed at $25.14 \mathrm{MHz}$ in $30-\%$ (w/v) solution in $\mathrm{D}_{2} \mathrm{O}$ at $100^{\circ} \mathrm{C}$ (256 scans): (a) PVA-A; (b) PVA-B. The sweep rate for each scan was 27 $\mathrm{ppm} / 250 \mathrm{sec}$.

are less than $0.06 \mathrm{ppm}^{13,16}$ Consequently, for the $\alpha$-methine group of PVA, the carbon nucleus is more sensitive to the difference of steric configuration than the corresponding proton. Furthermore, each of the major triad lines is partially resolved into pentad lines. Although the resolution and sensitivity are not good enough to permit accurate quantitative measurements, at least five of the possible ten pentad lines are discernible. It is noteworthy that the resolution of heterotactic and syndiotactic parts are slightly better than that of the isotactic. These phenomena were also observed in the ${ }^{13} \mathrm{C}-\left\{{ }^{1} \mathrm{H}\right\}$ NMR resonance of aromatic carbons of polystyrene and poly $(\alpha$-methyl styrene $) .^{25}$

The relative intensities of triad microtacticity of PVA determined from Figure 6 are tabulated in Table I compared with those determined from the ${ }^{1} \mathrm{H}$ spectra of PVAc. It is clear that the tacticity determined from the ${ }^{13} \mathrm{C}-\left\{{ }^{1} \mathrm{H}\right\}$ spectra coincides fairly well with that from the ${ }^{1} \mathrm{H}$ spectra. This fact shows that the nuclear Overhauser effect caused by the total proton decoupling does not affect the relative intensities among the peaks assigned to the same chemical species differing only in stereochemical configuration even for ${ }^{13} \mathrm{C}-\left\{{ }^{1} \mathrm{H}\right\}$ spectra. Consequently, one can conclude that the dominant relaxation mechanism of $\alpha$-carbon of PVA is the same regardless of its stereochemical configuration. The same conclusion has been also derived for many other polymers. ${ }^{3,5,8,25-26}$ One can assert here that the ${ }^{13} \mathrm{C}-\mathrm{NMR}$ analysis is superior to ${ }^{1} \mathrm{H}$ NMR as the mean of studying the configurational sequence of PVA.

The following relation

$$
4(m m)(r r) /(m r)^{2}=1
$$

appears to be satisfactory for PVA-B or PVAc$B$ as shown in the last column of Table $I$. The mechanisms of stereospecific polymerization in the PVA-B can therefore reasonably be assumed to be the Bernoulli trial process. ${ }^{27}$ For the PVA-A, however, the above relation is not true. Information about the higher order microtacticity is necessary in order to decide mechanisms in stereospecific polymerization of the PVA-A.

The ${ }^{13} \mathrm{C}-\left\{{ }^{1} \mathrm{H}\right\}$ resonances of the $\beta$-methylene carbon atoms of PVA consist of three main peaks as shown in Figure 7. These splittings cannot be interpreted by the diad configuration, but must be the overlapping of the six tetrad peaks. The position of the $\mathrm{mmm}$ tetrad resonance may be at the highest field peak, inferred from the chemical shift and intensity of the $\beta$ methylene resonance of PVA-A. The assignments of other peaks cannot be made at the present stage.

It may be worth mentioning that the triad line ordering for the $\alpha$-methine carbon resonance in PVA is isotactic, heterotactic, syndiotactic with increasing field strength, while that for the $\alpha$-methine proton resonance in PVA is reversed as mentioned before. In the case of polyacrylonitrile $^{26,28}$ and poly(vinyl chloride) ${ }^{26,29}$ the triad line ordering for the $\alpha$-methine carbon resonance is the same as that for the $\alpha$-methine proton, that is, syndiotactic, heterotactic, and isotactic with increasing field strength. In 


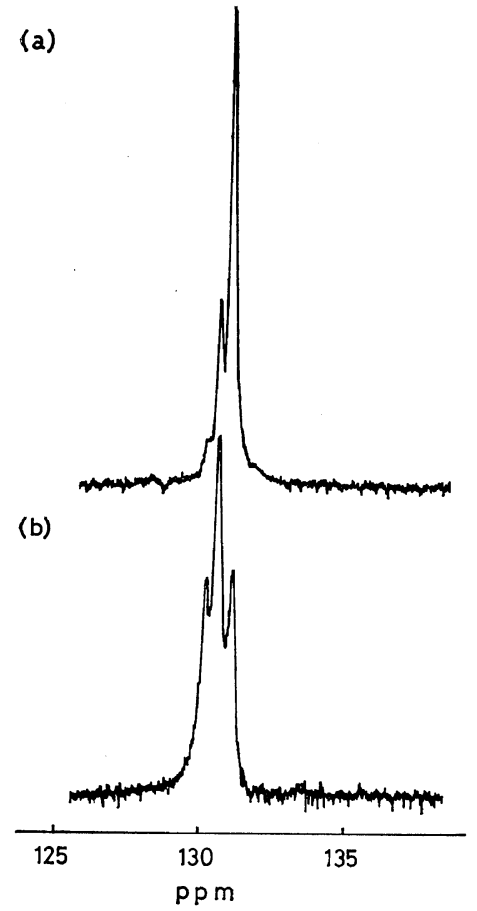

Figure 7. ${ }^{13} \mathrm{C}-\left\{{ }^{1} \mathrm{H}\right\}$ spectra of methylene carbon of PVA, observed under the same conditions as in Figure 6: (a) PVA-A; (b) PVA-B.

general, the configurational line ordering of ${ }^{1} \mathrm{H}$ NMR of the group in (or near) the main chain of vinyl polymers are affected by through-space magnetic interactions, local electric fields, and solvent effects, ${ }^{30}$ while that of ${ }^{13} \mathrm{C}$ NMR are mainly decided by the electron density of the $2 p$ electron. The configurational line ordering, however, may be strongly dependent on the skeletal form of the chain segment in solution, that is, on its conformation. For segments of $\alpha$-monosubstituted vinyl polymers with different side groups (where the side group has a moderate radius) and same steric configuration, the conformation in the usual solutions may be qualitatively similar. This means that the $\alpha$ methine group of different polymers in the segments of the same configuration will have similar conformational environments, and will then produce a similar relative chemical shift in ${ }^{13} \mathrm{C}$ or ${ }^{1} \mathrm{H}$ NMR. Since the triad line ordering of ${ }^{1} \mathrm{H}$ resonance of $\alpha$-methine proton is the same as that in PVA, poly(vinyl chloride), and polyacrylonitrile, and that of ${ }^{13} \mathrm{C}$ resonance of $\alpha$-methine carbon is also the same as that in poly(vinyl chloride) and polyacrylonitrile as mentioned above, it may be reasonably expected that the triad line ordering of ${ }^{13} \mathrm{C}$ resonance of $\alpha$-methine group in PVA is syndiotactic, heterotactic, and isotactic with increasing field strength. However the results are the reverse. This exceptional behavior of ${ }^{13} \mathrm{C}$ triad line ordering of PVA can be explained by its intra- and intermolecular hydrogen bonding and by an unusual solvent effect of water. It is well known that the molecules of PVA form intra- and intermolecular hydrogen bondings between the hydroxy groups of PVA and solvent water. ${ }^{31-33}$ Fukuroi, et al. ${ }^{33}$ have shown, in a conformational study of 2,4-pentandiol by means of NMR, that intramolecular hydrogen bonding plays an important role in stabilizing conformation and the stabilization by hydrogen bonding is larger in the meso isomer than in the racemic isomer. Thus the amount of hydrogen bonding in PVA may be larger in the isotactic parts than in the heterotactic or syndiotactic parts of the PVA chain. The hydrogen bonding causes a downfield shift of the ${ }^{13} \mathrm{C}$ resonance of the carbon atom which is directly bonded to the hydrogen bonding oxygen atom. ${ }^{34,35}$ From these discussions the ${ }^{13} \mathrm{C}$ triad line ordering of $\alpha$-methine carbon of PVA can be understood qualitatively. However it would be very difficult to discuss properly the trend in line ordering, because of the lack of detailed information on the local chain conformations of the polymer.

\section{Branching in PVA}

It is well known that the heterogeneous structures, such as 1,2-glycol sequences (headto-head arrangements of structural units) and branchings, are present to some extent in the PVA chain. The detection and the estimation of these heterogeneous structures in PVA are important for industrial applications. The 1,2glycol content can be determined accurately by the polarographic method ${ }^{36,37}$ and the titrimetric method. ${ }^{38}$

With regard to branching however, no experimental techniques to prove its existence in PVA are known. Two types of braching may 


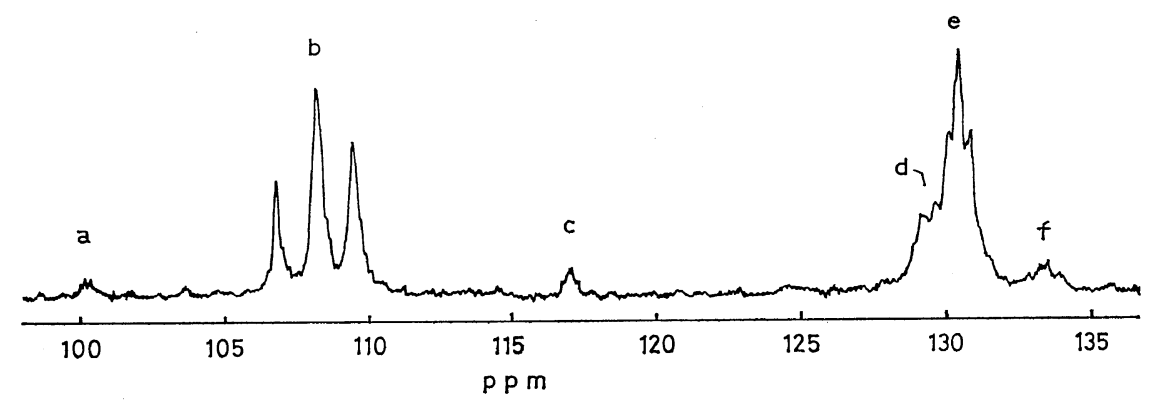

Figure 8. ${ }^{19} \mathrm{C}-\left\{{ }^{1} \mathrm{H}\right\}$ spectrum of PVA-C observed at $25.14 \mathrm{MHz}$ in $30-\%(\mathrm{w} / \mathrm{v})$ solution in $\mathrm{D}_{2} \mathrm{O}$ at $100^{\circ} \mathrm{C}(512$ scans). The sweep rate for each scan was $54 \mathrm{ppm} / 100 \mathrm{sec}$.

be possible, i.e., short and long chain branching. In this paper is reported the preliminary results of an attempt to detect the short chain branching in the PVA by the use of ${ }^{13} \mathrm{C}$-NMR. The sample PVA-C was used as a model polymer of PVA having short chain braching of the following type,

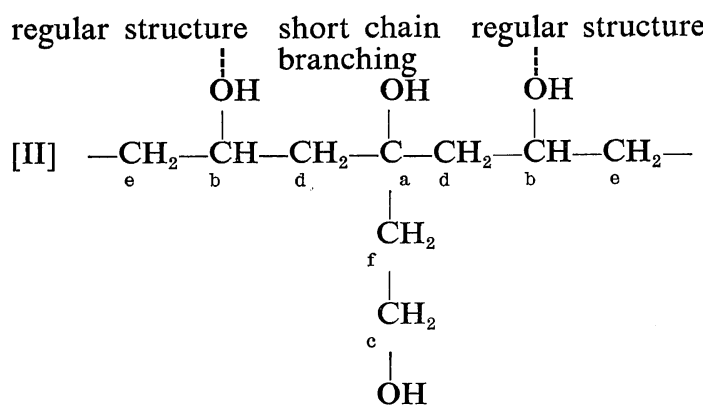

This type of branching is one of the most probable short chain types.

The reaction mechanisms for the formation of this type of braching in PVA may be an intramolecular chain transfer reaction at the growing chain end of PVAc. ${ }^{39,40}$ A ${ }^{13} \mathrm{C}-\left\{{ }^{1} \mathrm{H}\right\}$ full spectrum of PVA-C is shown in Figure 8. In spite of the low resolution the resonances assingned to the structure corresponding to short chain branching are clearly observed in this spectrum. On the basis of the magnitudes of the chemical shifts and the peak intensity these resonances were assigned to corresponding structures as shown in Figure 8 (see the structural equation [I] and $[\mathrm{II}]$, too). The resonances $b$ and e were assigned to the carbons in the regular PVA structure and the resonances a, c, d, and $f$ to those in the short branching. The resonances a and c may shift to the lower field,

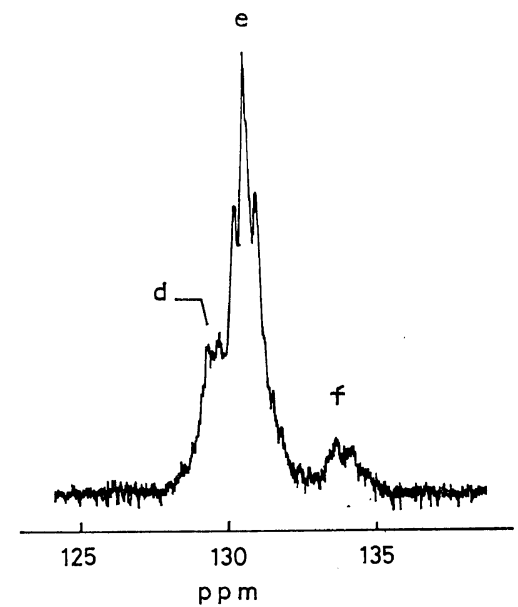

Figure 9. ${ }^{13} \mathrm{C}-\left\{{ }^{1} \mathrm{H}\right\}$ spectrum of the upper field part of PVA-C observed at $25.14 \mathrm{MHz}$ in $30-\%$ (w/v) solution in $\mathrm{D}_{2} \mathrm{O}$ at $100^{\circ} \mathrm{C}(512$ scans). The sweep rate for each scan was $54 \mathrm{ppm} / 250 \mathrm{sec}$.

because these carbons are adjacent to the hydroxyl groups. The distinction between the resonances $a$ and $c$ was made by comparison of peak intensities and the line shape variance according to the variance of the power of the proton decoupling. The resonance of the quarternary carbon at the branching point is not very obvious because of the lack of the signal enhancement due to the nuclear Overhauser effect. More interesting is the methylene carbon resonances at $c a .127 \sim 135 \mathrm{ppm}$, and in Figure 9 is shown a refined methylene carbon spectrum of this part. The ratio estimated from the intensity of the spectrum is 2.0 for the resonances $d$ to $f$ and is 7.5 for the resonances. e to $f$. The former is in close agreement with that expected from the structure [II] and the 
latter is comparable with that of the copolymer composition ratio as mentioned in the experimental section. Therefore it may be possible to determine the short branch content of type [II] by comparing the intensity of the resonance $e$ with that of $d$ or $f$. In the case of long chain branching, the three methylene carbons adjacent to the braching point should be magnetically equivalent to each other and the resonance of these carbons may be superimposed on the resonance $d$. If there is both long and short chain branching, the intensity of the resonance $d$ is greater than twice that of $f$. In principle it may be possible to estimate separately the content of short and long chain branching in a PVA chain by comparing the intensities of the resonances at $d$, e, and $\mathrm{f}$. It is necessary in practice to carry this accumulation many times to estimate the content of branching in ordinary PVA, since the number of branch points per 100 monomer units in ordinary PVA may be less than unity. The relatively large ${ }^{13} \mathrm{C}$ chemical shifts and the latest remarkable developments in NMR instruments, for example, Fourier transform technique, encourage one to expect that the detection and estimation of small fractions of heterogeneous structures in polymers may be possible in the near future. Extensive work is in progress on the heterogeneous structure of PVA using the ${ }^{13} \mathrm{C}$ NMR and will be reported elsewhere.

\section{REFERENCES}

1. J. Schaefer, Macromolecules, 2, 210, 533 (1969); 4, 98, 105, 107, 110 (1971).

2. M. W. Duch and D. M. Grant, ibid., 3, 165 (1970).

3. L. F. Johnson, F. Heatley, and F. A. Bovey, ibid., 3, 175 (1970).

4. W. O. Crain, Jr., A. Zambelli, and J. D. Roberts, ibid., 4, 330 (1971).

5. C. J. Carman, A. R. Tarpley, Jr., and J.H. Goldstein, J. Amer. Chem. Soc., 93, 2864 (1971); Macromolecules, 4, 445 (1971).

6. A. Zambelli, G. Gatti, C. Sacchi, W. O. Crain, Jr., and D. Roberts, Macromolecules, 4, 425 (1971).

7. C. J. Carman and C.E. Wilkes, Rub. Chem. Tech., 44, 781 (1971).

8. Y. Inoue, A. Nishioka, and R. Chûjô, Poly- mer J., 2, 535 (1971).

9. W. J. Horsley, H. Sternlicht, and J. S. Cohen, J. Amer. Chem. Soc., 92, 680 (1970).

10. P. J. Green and E. B. Whipple, ACS Polym. Preprints, 12, 354 (1971).

11. F. A. Bovey, E. W. Anderson, D. C. Douglass, and J. A. Manson, J. Chem. Phys., 39, 1199 (1963).

12. K. Fujii, Y. Fujiwara, and S. Fujiwara, Makromol. Chem., 89, 278 (1965).

13. K. C. Ramey and N. D. Field, J. Polym. Sci., Part B, 3, 63, 69 (1965).

14. S. Murahashi, S. Nozakura, M. Sumi, H. Yuki and K. Hatada, ibid., Part B, 4, 65 (1966).

15. K. C. Ramey and D. C. Lini, ibid., Part B, 5, 39 (1967).

16. K. C. Ramey, D. C. Lini, and G. Statton, ibid., Part A, 5, 257 (1967).

17. H. L. Frisch, C. L. Mallows, and F. A. Bovey, J. Chem. Phys., 45, 1565 (1966).

18. A. Danno and N. Hayakawa, Bull. Chem. Soc. Japan 35, 1748 (1962).

19. W. C. Tincher, Makromol. Chem., 85, 46 (1965).

20. J. Bargon, K. -H. Hellwege, and U. Johnsen, ibid., 85, 291 (1965).

21. S. Murahashi, S. Nozakura, and M. Sumi, $J$. Polym. Sci., Part B, 3, 245 (1965).

22. S. Nozakura and H. Iimuro, Paper read at SPSJ 21st Annual Meeting, Tokyo, Japan, May 1972.

23. A. W. Overhauser, Phys. Rev., 92, 411 (1953).

24. F. Bloch, ibid., 93, 944 (1954).

25. Y. Inoue, A. Nishioka, and R. Chûjô, Makromol. Chem., 156, 207 (1972).

26. Y. Inoue and A. Nishioka, Polymer J., 3, 149, 246 (1972).

27. R. Chûjô, J. Phys. Soc. Japan, 21, 2669 (1966).

28. K. Matsuzaki, M. Okada, and T. Uryu, $J$. Polym. Sci., Part A-1, 9, 1701 (1971).

29. F. Heatley and F. A. Bovey, Macromolecules, 2, 241 (1969).

30. W. M. Ritchey and F. J. Knoll, J. Polym. Sci., Part B, 4, 853 (1966).

31. C. W. Bunn, Nature, 161, 929 (1948).

32. S. Murahashi, H. Yuki, T. Sano, U. Yonemura, H. Tadokoro, and Y. Chatani, J. Polym. Sci., 62, S 77 (1962).

33. T. Fukuroi, Y. Fujiwara, S. Fujiwara, and K. Fujii, Ann. Chem., 40, 879 (1968).

34. G. E. Maciel and G. C. Ruben, J. Amer. Chem. Soc., 85, 3903 (1963).

35. G. C. Maciel and R. V. James, ibid., 86, 3893 (1964).

36. S. Imoto, J. Ukita, and T. Konami, Kobunshi 
Y. Inoue, R. Chûjô, A. Nishioka, S. Nozakura, and H. Iimuro

Kagaku (Chem. High Polymers), 14, 214 (1957). 39. I. Sakurada, Y. Sakaguchi, and Z. Shiik, 37. K. Shibatani, M. Nakamura, and Y. Oyanagi, ibid., 26, 118 (1969). Kobunshi Kagaku (Chem. High Polymers), 21, 289 (1964).

38. H. E. Harris and J. G. Pritchard, J. Polym. 40. M. J. Roedel, J. Amer. Chem. Soc., 75, 6110 Sci., Part A, 2, 3673 (1964). (1953). 